\title{
Review of Intramedullary Interlocked Nailing in closed \& grade I open Tibial fractures
}

\author{
Kumar Anshuman ${ }^{1}$ G.S. Patnaik ${ }^{2}$ S.Nag ${ }^{3}$ \\ ${ }^{1}$ Asst Professor, ${ }^{2}$ Prof And Head, Dept Of Orthopedics, ${ }^{3}$ Prof HOD \\ Dept Of Anesthesia,Narayan Medical College Jamuhar, Sasaram Bihar
}

Key words: Tibia Nailing, interlocked nailing, grade I open fracture Tibia.

\section{Introduction}

Tibial shaft fractures are the most common long bone fractures in adults and are usually caused by high-energy trauma. The management of tibial diaphyseal fractures has always been a challenge on account of its subcutaneous location [8], associated severe soft tissue injuries and many of these being open fractures. E.A.Nicoll [33] stated that, "Fractures of the tibia are important for two reasons: (1) they are common, and (2) they are controversial, and anything which is common and controversial must be important".

In this Study attempt has been made to critically evaluate the outcome of closed intramendullary interlocked nailing in tibial fractures in relation to union, functional healing and the complications of the procedure [11].

This procedure has two advantages, that it controls the rotational stability of fracture fragments, Better correction of angulation deformity, Minimal damage to soft tissue envelope of bone thereby preserving blood supply of the bone, Minimal blood loss, Can be used not only in the mid shaft fractures but also in more proximal and distal fractures $[30,31,32]$, Widely accepted as primary method of fixation in grade I open fractures. [39]. However, this method of treating tibial fractures is not free of complications viz.:

General complications: Deep Vein Thrombosis [12], Pulmonary Embolism, Pneumonia, Infections etc.

\section{Materials And Methods}

In this study we have included cases of closed/open grade-I tibial shaft fractures in adults, treated by closed intramedullary interlocked nailing at Narayan Medical College \& Hospital Jamuhar, Sasaram, between November 2011 to January 2013. Retrospective(18) and Prospective(12)cases were studied. Retrospective cases included cases from November 2010 to October 2011. 30 cases formed the basis of this study. All the cases were followed up till the union of fracture was achieved. They were evaluated clinically, radiologically and functionally. The data thus collected was tabulated and analyzed to draw the conclusions.

Cases were selected keeping in view the following criteria: -

\section{Inclusion criteria:}

1. Patients from either sex of above 16 years.

2. Isolated fracture tibia.

3. Closed or open Gustilo grade-I, fractures of both bones leg.

4. All those fractures of tibia which are $7 \mathrm{~cm}$ distal to knee and $4 \mathrm{~cm}$ proximal to the ankle joint.

5. Unilateral or bilateral tibial fractures.

\section{Exclusion criteria:}

1. Patient less then 16 years of age.

2. Any associated fracture in the same or opposite lower limb.

3. Fractures proximal to $7 \mathrm{~cm}$ of tibia or Distal to $4 \mathrm{~cm}$ of tibia.

Open fractures were classified according to the classification of Gustilo and Anderson. Other investigations done included a complete blood count with ESR, Prothrombin time, Activated partial thromboplastin time, urine examination, blood urea nitrogen, Serum creatinine, random blood sugar, blood grouping and matching and chest X-ray. Any other investigation as deemed necessary was carried out

\section{Management}

Immediately after admission, the patients were administered appropriate dose of analgesic to relieve pain and injured limb was immobilized in above knee Plaster of Paris (POP) back slab. All the patients were 
operated as early as possible depending upon the local/general condition of the patients. All the patients were given a broad-spectrum antibiotic, mostly a third generation cephalosporin peroperatively and repeated after 6-8 hours postoperatively.

\section{Operative Technique}

The patients were operated upon using general or regional anesthesia as deemed appropriate by the anesthetist. A tourniquet was applied over the thigh and pressure raised to $250 \mathrm{~mm} \mathrm{Hg}$. Para patellar or splitting of patellar tendon was done, reaming was done in most of the cases. Length were measured by placing radioopaque ruler.

Rotational alignment was evaluated by aligning the iliac crest, patella, and the second ray of foot. Distal locking was done using free hand technique and proximal locking was done through the jig attached to the nail insertion device under fluoroscopy control. All wounds were closed and antiseptic dressing was done.

\section{Post-operative Care}

The leg was elevated an above knee POP posterior slab Dressing of surgical wound and drain removal (if any) was done 48 hours after surgery, A post-operative radiograph was taken for documentation, Partial weight bearing was started when there was clinical evidence of fracture healing, usually about 3 weeks, Full weight bearing was started when there was radiological evidence of fracture union, usually about 3-4 months,

During each visit the patients were evaluated both subjectively and objectively, using the Karlstorm and Olerud 36-point clinical grading system and radiological evaluation of leg [24]. This system evaluated the patients both subjectively and objectively and thus gave a comprehensive picture of the patient's condition. An overall result of excellent, good, acceptable or poor was determined according to the following criteria-

Excellent-Score of 3 in all the factors listed above.

Good- Score of 2 or more in all the factors listed above.

Acceptable- Score of 1 in one factor and scores of 2 or 3 in all other factors.

Poor-Score of 1 in more than one factor.

A total of 30 cases of closed and open grade-I tibial shaft fractures were operated. Retrospective and prospective cases were included. The present study is based on observations obtained in 30 cases. The mean age of patients was 41.5 Yrs.Transverse fracture was the most common occurring in $18(60.0 \%)$ patients followed by Oblique fractures in $8(26.66 \%)$ patients. 24 patients $(80 \%)$ sustained closed tibial shaft fractures while 6 patients sustained an open grade I fracture.Reaming was done in 21 (70 \%) patients while unreamed tibial nail was put in 9 patients. $10 \mathrm{~mm}$ size nail was used in most (14/30) patients.Dynamic locking was done in $21(70 \%)$ patients and static locking was done in 8 patients. No patients had valgus or varus deformity radiologicaly of more than 10 degrees. Most (86.66\%) patients needed no immobilization. 3 patients had an above knee POP slab while 1 patient had a below knee POP slab. Most patients (22) started partial weight bearing within 9 weeks post-surgery followed by 4 patients between $9-12$ weeks and another 4 patients after 12 weeks post-surgery. The average interval between surgery and partial weight bearing was 9.06 weeks ( 3 to 32 weeks). Most patients (24) started full weight bearing within 24 weeks after surgery. 5 patient started full weight bearing between 24 to 36 weeks and only one patient on account of old age started full weight bearing after 36 weeks. Dynamization was done in 4 patients. 28 patients had complete union while only 2 had delayed union.

According to Karlstrom and Olerud [23, 25] functional scoring system all patients had excellent results of pain evaluation. 28 patients had a score of 3 and only 2 patients had a score of 2 with regards to Previous sports activity. 20 patients had a score of 3,8 patients had a score of 2 and only 2 patients had a score of 1 with regards to walking capacity. 17 patients had a score of 3,10 patients had a score of 2 and only 3 patients had a score of 1 . with regards to work limitation. No patient had any obvious deformity at follow up. No patient had any limb length discrepancy at follow up. $93.33 \%$ patients had less than 10 degrees loss of knee motion while only 2 had between 10-20 degrees loss of motion. All patient had almost full range of ankle movement. All patient had almost full range of subtalar motion. $27(90 \%)$ patients had at least $140^{\circ}$ range of movement, $3(10 \%)$ patients at least $100^{\circ}$ range of movement and no patient had less than $100^{\circ}$ range of motion at the knee joint.

Most patients had bony union radiologically by 24 weeks and another 5 between 24-36 weeks. Only 2 patients had infection at proximal insertion site at follow up. One patient had a broken implant at 24 weeks when full weight bearing was started. He was later managed with an above knee POP cast with implant left in situ. The bone united at 6 months later. The proximal half of the broken nail was removed there after. No patient required secondary surgeries for surgical complications. According to Karlstrom \& Olerud functional scoring system 17 patients had excellent overall functional results, 10 had good results, 2 had acceptable results only one patient had poor result on account of her old age and poor health condition. 2 patients had acceptable results on account of poor patient compliance to follow postoperative physiotherapy. 


\section{Discussion}

Tibial shaft fractures are the most common long bone fractures in adults and are usually caused by high-energy trauma [7, 8, 9]. Moreover, its location and the fact that its anteromedial border is subcutaneous renders the bone susceptible to injury. Operative treatment of tibial shaft fractures $[10,11,12,27,28,29]$ is disputed because impressive results are achieved by closed reduction, casting and functional bracing of these fractures as shown by Sarmiento et.al [35, 36]. However with cast treatment, loss of reduction which subsequently introduces malunion and nonunion is not uncommon [1]. The objections to operative management have however been mainly related to plate osteosynthesis [22] because plating of the tibial shaft fracture may induce an unacceptably high risk of infection $[2,12]$. With the invention of the interlocked nail there was a great achievement in the nailing technique as the rotational stability could also be achieved [3, 4, 5]. Also the dynamization of the nail was not problem due to presence of slot for dynamic nail proximally [24, 25, 26]. Recent emphasis has been given to treating these kinds of fractures with antomical restoration of alignment, stable and rigid internal fixation with rotational stability and early weight bearing. The aim of operative treatment is to obtain a proper anatomical alignment, early knee mobilization exercises early weight bearing even before the bony union is achieved $[14,15,16,17,39]$.

Reamed intramedullary nailing of the tibia for acute fractures offers significant benefits to the patients in the form of short hospital stay, early range of motion .and exercises and weight bearing without immobilization in plaster and thereby consequent good functional results in a majority of these controversial fractures [18, 19, 20, 22].

\section{Summary And Conclusions}

Patients in our study were mainly middle aged. Males dominated our study. The variables like age and sex did not influence the results significantly. High velocity road traffic accidents were the main cause of injury. Distal $1 / 3^{\text {rd }}$ tibial shaft fractures were more common followed by middle $1 / 3^{\text {rd }}$, upper $1 / 3^{\text {rd }}$ being the least common. Transverse fractures dominated the study followed by oblique and spiral fractures. The 'classification' variable did not demonstrate any statistical correlation with functional results. No obvious correlation of days between injury and operation with outcome of results was seen. However delay in operation causes greater soft tissue swelling making the management more difficult. In comminuted fractures, rigid fixation like closed intramedullary interlocked nailing gave better functional results as it is a minimally invasive procedure which does not require opening of the fracture site thus haematoma is not drained. Moreover the length and rotation of the limb is maintained and at the same time there is angular correction. However, we also had our share of unsatisfactory results with regards to angulation deformity, delayed union, mal-union and non-union. Knee pain was the commonest complication seen. This was due to slightly protruding proximal end of the nail, which was found to be jetting out just beneath the patellar tendon, which can be attributed to poor nailing technique. In the distal and proximal third there was some degree of angulation. So, the surgeon should be careful about the alignment while locking proximally and distally.

Finally we conclude that closed intramedullary interlocked nailing for acute tibial fractures gives excellent results in closed and grade-I open fractures if done judiciously and with proper technique. Moreover it offers significant benefits to the patient in the form of short hospital stay, early range of motion exercises, also partial weight bearing can be started early, so both function and healing of fracture goes side by side and thereby, consequent good functional results were achieved in a majority of these fractures.

[1]. Abbas Hallaj Karldani, Hans Granhed, Bjorn Edshage, Ragar Jerre and Jorma Styf; Displaced tibial shaft fracture, A prospective randomized study of closed tramedullary tibial nailing versus cast treatment in 53 patients. Acta Orthp. Scand. 2000 April; 71(2):160-7.

[2]. Alberts KA, Loohagen G, Einarsdottir H.; Open tibial fractures: faster union after unreamed nailing than external fixation. Injury. 1999 Oct; 30(8): 519-23.

[3]. Alho A., Molster A., Thorensen N.R. Gjerdet, Ekeland A., Folleras G., Haukebo A., Stromsoe K. \& Viste A.; the effect of rotational stability of the intramedullary nailing on bone healing. Acta. Orthop. Scand. 57, 575, 1986.

[4]. Anglen JO, Blue JM; A comparison of reamed and unreamed nailing of the tibia. J. Trauma. 1995 Aug; 39(2): 351-5.

[5]. Barry L.Riemer, MD, Shaul Sagiv, MD, Spencer L.Butterfield, MD, Charles J.BurkeIII, MD; Tibial Diaphyseal Nonunions After External Fixation Treated with Nonreamed Solid Core Nails. Orthopaedics.1996 Feb; 19(2); 109-16.

[6]. Bhandari M, Guyatt GH, Swiontkowski MF, Schemitsch EH.; Treatment of open fractures of the shaft of the tibia. JBoneJointSurgBr.2001Jan; 83(1): 62-8.

[7]. Campbell's Operative Orthopaedics; Tenth Edition, Vol (3), 2754-2782.

[8]. Chaurasia B.D: Anatomy of the tibia joint: Human anatomy, $3^{\text {rd }}$ Edition Vol. 2, 80-101.

[9]. Clinical Oriented Anatomy; Keith L.Moore, Third Edition, 432-460.

[10]. Costa P, Carretti P, Giancecchi F, Pignedoli P, Rotini R, Trataglia I.; The locked Grosse-Kempf intramedullary nail in the treatment of diaphyseal and metaphyseal fractures of the femur and the tibia. Ital J Orthop Traumatol. 1998 Dec; 14(4): 475-82.

[11]. Court-Brown C.M., J.Christie, McQueen MM; closed intramedullary tibial nailing its use in closed and type I open fractures. J.Bone Joint Surg Br. 1990 Jul; 605-11. 
[12]. Court-Brown C.M., Keating J.F., McQueen M.M.; infection after intramedullary nailing of tibia incidence and protocol for mangement. J bone Joint Surg Br. 1992 Sep; 74(5): 770-4.

[13]. De Smet K, Mostert AK, De Witte J, De Brauwer V, Verdonk R.; Closed intramedullary tibial nailing using the MarchettiVicenzi nail. Injury. 2000 Oct; 31(8): 597-603.

[14]. Ekeland A, Thoresen BO, Alho A, Stromsoe K, Folleras G, Haukebo A.; Interlocking intramedullary nailing in the treatment of tibial fractures. A report of 45 cases. Clin Orthop. 1988 Jun;(231): 205-15.

[15]. Ekeland, MD. M.Sc.D., Thoreses Bjorn O, M.D., Alho Antti Alho, M.D., M.Sc.D., Stromsoe Knut, M.D., Folleras Gunnar, M.D., \& Haukebo Arne, M.D.; Interlocking Intramedullary Nailing in the Treatment of Tibial Fractures. A Report of 45 Cases. Clin Orthop. Jun; 231: 205-215, 1988

[16]. Gregory M. Georgiadis, MD. Nabil A. Ebraheim, MD, and Michael,MD; Displacement of the Posterior Malleolus during intramedullary Tibial Nailing. J Trauma. 1996 Dec; 41(6): 1056-8.

[17]. Gregory P, Sanders R.; The treatment of closed, unstable tibial shaft fractures with unreamed interlocking nails. Clin Orthop. 1995 Jun;(315): 48-55.

[18]. Harlan S. Chiron, MD; open fractures of the shaft of tibia treated by Intramedullary Nailing. Bull Hosp. Joint Diseases Orthop Inst. 1982 spring; 42(1): 92-102.

[19]. Howard MW, Zinar DM, Stryker WS; The use of the Lottes nail in the treatment of closed and open tibial shaft fractures. Clin Orthop. 1992 Jun;(279): 246-53. Review.

[20]. Jahnke AH Jr, Fry PJ, Swanson KR, Watson RC, Tapper EM.; Treatment of unstable tibial shaft fractures by closed intramedullary nailing with flexible (Ender-type)pins. Clin Orthop. 1992 Mar;(276): 267-71.

[21]. Jean-Yves DE LA Caffiniere, Francois Pelisse, Marc DE LA Caffiniere; locked intramedullary flexible osteosynthesis, A mechanical and clinical study of a new pin fixation device. J Bone Joint Surg Br. 1994 Sep; 76(5): 778-88.

[22]. Johnson EE, Simpson LA, Helfet DL; Delayed intramedullary nailing after failed external fixation of the tibia. Clin Orthop. 1990 Apr;(253): 251-7.

[23]. Kalstrom Goran \& Olerud Sven; Fractures of the tibial shaft, A critical evaluation of treatment alternatives. Clin Orthop. \& Related Research 1974, Nov-Dec;(105): 82-115.

[24]. Kalstrom Goran \& Olerud Sven; Percutaneous pin fixation of open tibial fractures. J bone Joint Surg Am. 1975; 57A(7): 915924.

[25]. Kalstrom Goran \& Olerud Sven; The spectrum of intramedullary nailing of the tibia. Clin Orthop. \& Related Research 1986, Nov; (212): 101-112.

[26]. Keating JF, Gardner E, Leach WJ, Macpherson S, Abrami G.; Management of tibial fractures with the orthofix dynamic external fixator. J R Coll Surg Edinb. 1991 Aug; 36(4): 272-7.

[27]. Kok-Long Pan, Shukar M.H. and Ali Noor Ghani M.; Locked intramedullary nailing for complex Non Union of the tibia.Injury.1994 Dec; 25(10); 655-7.

[28]. Lawerence B. Bonem MD, DanielSucato, MD, Philip M. Stegemann, MD, and Bernhard J. Rohrabacher, MD, Buffalo, New York; Displaced Isolated Fractures of the Tibial Shaft treated with Either Cast or Intramedullary Nailing. J Bone Joint Surg Am. 1997 Sep; 79(9): 1336-41.

[29]. Maurer DJ, Merkow RL, Gustilo RB; Infection after intramedullary nailing of severe open tibial fractures initially treated with external fixation. J Bone Joint Surg Am. 1989 Jul; 71(6): 835-8.

[30]. Megas P. Panagiotopoulos E, Skriviliotakis S, Lambiris E : Intramedullary nailing in the treatment of aseptic tibial nonunion. Injury. 2001 Apr; 32(3): 233-9.

[31]. Melcher G.A., Ch.RyfA. Leuteeggerand, Ruedi Th.; Tibial fracture treated with AO unreamed tibial nailing. Injury.1993, Jul; 24(6): 407-10.

[32]. Michael W. Chapman, MD; the role of intramedullary fixation in open fractures. Clin Orthop. 1986 Nov;(212): 26-34.

[33]. Muller, M.E.: Internal Fixation for Fresh Fractures and for Non-Union. Proc. Royl. Soc. Med. 56:455, 1963.

[34]. Nicoll E.A., CBE, MA, MD, FRCS; Closed and Open Management of Tibial Fractures. Clin Orthop. 105:144-153, 1974.

[35]. Sarmianto Augusto, M.D., Philip A. Sobol., M.D., Andrew L. Sew Hoy, M.D., Steven D.K. Ross, M.D., Walter L. Racette, C.P.O., \& Richard R. Tarr, M.S.; Prefabricated Functional Braces for the Treatment of Fractures of the Tibial Diaphysis.; J Bone Joint Surg Am. 1984 Dec;66(9):1328-39.

[36]. Sarmiento Augusto; A Functional Below-the-Knee brace for tibial fractures. A report on its use in one hundred thirty five cases. J. Bone \& joint Surg., 52-A, 295-311, March 1970.

[37]. Sergeant ID, Lovell M, Casserley H, Green AD; The AO unreamed tibial nail: a 14-month follow-up of the1992 TT experience. Injury. 1994 Sep; 25(7): 423-5.

[38]. Siebenrock KA, Gerich T, Jakob RP; Sequential intramedullary nailing of open tibial shaft fractures after external fixation. Arch. Orthop. Trauma. Surg. 1997; 116(1-2): 32-6.

[39]. Zucman J. \& Maurer P; TWO-LEVEL FRACTURES OF THE TIBIA. Results in thirty-six cases treated by blind nailing. J Bone Joint Surg Br.1969 Nov; 51B(4): 686-93. 